\title{
Effects of obesity upon genioglossus structure and function in obstructive sleep apnoea
}

\author{
M. Carrera*, F. Barbé*, J. Sauleda*, M. Tomás\#, C. Gómez", C. Santos ${ }^{+}$, A.G.N. Agustí*
}

Effects of obesity upon genioglossus structure and function in obstructive sleep apnoea. M. Carrera, F. Barbé, J. Sauleda, M. Tomás, C. Gómez, C. Santos, A. G. N. Agustí. (C) ERS Journals Ltd 2004.

ABSTRACT: Obesity is a common feature of the obstructive sleep apnoea syndrome. It can influence the structure and function of skeletal muscles. However, its effects upon the upper airway muscles have not been explored directly.

This study assessed the structure and function of the genioglossus in patients with obstructive sleep apnoea syndrome and in healthy subjects (with and without obesity, defined by a body mass index $>30 \mathrm{~kg} \cdot \mathrm{m}^{-2}$ ). Further, to investigate the effects of continuous positive airway pressure (CPAP) treatment, patients with obstructive sleep apnoea syndrome after at least 1 yr under CPAP were also studied.

The study found that obese and nonobese patients showed different in vitro geniglossus endurance properties. In obese patients, geniglossus endurance was indistinguishable from normal while, nonobese patients, at diagnosis, showed increased genioglossus fatigability; this was not observed in patients treated with CPAP. By contrast, patients with obstructive sleep apnoea syndrome showed at diagnosis a higher percentage of type II fibres than controls and patients under CPAP treatment independently of obesity. This difference is mainly due to a predominance of subtype IIb fibre. This difference was not observed in the group of patients treated with CPAP. Genioglossus twitch force was normal in all patients.

These results suggest that different pathogenic mechanisms may underlie the development of obstructive sleep apnoea syndrome in obese and nonobese patients. This observation may have potential clinical implications.

Eur Respir J 2004; 23: 425-429.
*Servicios de Neumología, ${ }^{\#}$ Otorhinolaryngology, Anatomía Patológica, and ${ }^{+}$Unidad de Investigación, Hospital Universitario Son Dureta, IUNICS, Palma de Mallorca, Spain.

Correspondence: F. Barbé

Servicio de Neumologia

Hospital Universitario Son Dureta

C/Andrea Doria, 55

07014 Palma de Mallorca

Spain

Fax: 34971175228

E-mail: fbarbe@hsd.es

Keywords: Muscle

muscle contraction

muscle fibres

upper airway resistance

Received: October 302002

Accepted after revision: October 12003

Supported, in part, by FIS 95/1510, BAE 97/5490, Carburos metálicos, Air Products, ABEMAR, Red RESPIRA and grant RTIC C03/11.
The obstructive sleep apnoea syndrome (OSAS) is characterised by the repetition of episodes of pharyngeal closure during sleep. The pathogenesis of these episodes is not fully understood [1]. Ultimately, the maintenance of pharyngeal patency depends on the equilibrium between occluding and dilating forces [1]. Among the latter, the activity of the pharyngeal dilator muscles is of paramount importance.

The genioglossus (GG) is the most important pharyngeal dilator muscle in humans [2, 3]. GG abnormalities can therefore play an important role in the pathogenesis of OSAS $[3,4]$. The current authors previously showed that the structure and function of the GG is abnormal in patients with OSAS [5]. Compared to healthy controls, the GG in patients with OSAS had a higher proportion of type II fibres and enhanced in vitro fatigability [5]. Interestingly, these structural and functional abnormalities were fully normalised by treatment with continuous positive airway pressure (CPAP), suggesting that they were a consequence (not a cause) of the disease [5].

Obesity is a common clinical feature of OSAS $[1,6]$. It can influence both the structure [7] and function [8] of skeletal muscles. However, to the best of the authors' knowledge, its effects upon the upper airway muscles have not been directly addressed by previous studies in the field [5, 9-11]. A retrospective analysis of the current authors' data [5] suggested that the function of the GG in obese and nonobese patients with OSAS may be different. Accordingly, the current authors' previous study was extended (by including new patients) to specifically investigate the effects of obesity upon the structure and function of GG in patients with OSAS, and the potential effects of CPAP in obese versus nonobese patients with OSAS.

\section{Material and methods}

Prospectively 13 patients with OSAS attended at the sleep unit from January 2000 to November 2001 who showed sleep respiratory disturbances were included. The diagnosis of OSAS was established during a full, supervised, standard polysomnographic study (Ultrasom Nicolette, Madison, WI, USA) [12], which included recording of oronasal flow by thermocouples mounted on nasal prongs, thoracoabdominal movements by strain gauges, electrocardiogram, submental electromyogram, electro-occulogram, electroencephalogram (C4 A1, C3 A2) and oxygen saturation (Criticare Systems Inc., Milwaukee, WI, USA). Apnoea was defined as airflow cesation for $>10 \mathrm{~s}$, and hypopnoea as an airflow reduction $>50 \%$ followed by a oxygen desaturation $>4 \%$. GG biopsy was also performed in another group of 10 OSAS patients

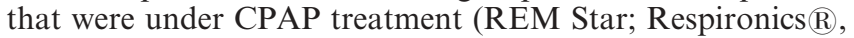
Madison, WI, USA) for at least $1 \mathrm{yr}$. CPAP compliance with treatment was confirmed by the timer built up in the CPAP device. Previously, the GG function and structure of 16 patients from that 23 group, was reported [5].

Control subjects were volunteers that required subglottic surgery due to malignant $(n=12)$ or benign lesions $(n=1)$. In all 
of them, OSAS was clinically excluded [12]. To avoid a potential influence of sex upon muscle structure and/or function [13] only male subjects were studied. Participants were grouped according to the presence or absence of OSAS (patients/controls), obesity (defined by a body mass index (BMI) higher than $30 \mathrm{~kg} \cdot \mathrm{m}^{-2}$ ) [14] and treatment status at the time of GG biopsy (none/CPAP) (table 1). Written consent was obtained from all participants and the Ethics Committee of Hospital Universitario Son Dureta, Palma de Mallorca approved the protocol.

\section{Lung function}

Forced spirometry (Warren E. Collins, Braintree, MA, USA) was obtained in all participants according to the SEPAR recommendations [15]. Reference values were those of a Mediterranean population [16].

\section{Genioglossus biopsy}

In 21 of the 23 patients with OSAS, the GG biopsy was obtained under local anaesthesia (1\% lidocaine with epinephrine). In no patient was anaesthesia injected in or near the site of biopsy. Through a $3 \mathrm{~cm}$ wide horizontal incision, $2 \mathrm{~cm}$ below the inferior limit of the chin, the milohyoid muscle was exposed and separated vertically in the midline. Then, the GG muscle was identified (close to the inner aspect of the mandible) and a piece of 4 by $4 \mathrm{~mm}$ (weighty 100-300 mg) was resected and sent to the laboratory, covered by a saline-soaked gauze. In all the control subjects, and in the remaining two patients with OSAS, the GG biopsy was obtained under general anaesthesia (propofol, midazolam and fentanyl) following the same surgical technique. In all participants, the GG biopsy was excised without the use of electrocautery. Complications derived from the procedure were always minor (local pain or limited bruise).

\section{In vitro functional studies}

Muscle strips were mounted immediately after biopsy in an organ bath (Radnoti Glass Technology, California, USA) containing standard Krebs-Ringer solution gassed with $95 \%$ oxygen and 5\% carbon dioxide, and heated at $37^{\circ} \mathrm{C}$ [17-19]. One end of the strip was tied to an immobile hook and the other to a calibrated high-sensitivity isometric force transducer (Radnoti Glass Technology, California, USA). Once in the tissue bath, muscle fibre length was adjusted by the micropositioner until maximal isometric twitch force responses were obtained (optimal fibre length (Lo)). Muscle strips were always stimulated (Model S-48, Grass Instruments Co, Mass, USA) with supramaximal pulses of $1.0 \mathrm{~ms}$ delivered through platinum electrodes (Radnoti Glass Technology, California, USA). All studies were performed at Lo, after an equilibration period [5]. Muscle force production was recorded for later analysis (Atlantis/Pegasus, Lakeshore Tech, Inc. Chicago, USA) of the maximum twitch tension and resistance to fatigue $[5,9,20,21]$. The absolute maximal forces were normalised to muscle cross-sectional area, as previously described [19].

\section{Fibre-type distribution}

After the functional protocol, GG samples were frozen in isopentane cooled with liquid nitrogen, and stored at $-70^{\circ} \mathrm{C}$ until analysis. Then, $6 \mu \mathrm{m}$ thick sections of the biopsies were cut in a cryostat $\left(-20^{\circ} \mathrm{C}\right)$ (Cryocut 1800 , Leica Instruments, Bensheim, Germany). Type I ("slow twitch") and type II ("fast twitch") fibres (and their subtypes IIa and IIb) were identified by the standard adenosine triphosphatase (ATPase) (at 9.4 and $4.6 \mathrm{pH}$ pre-incubation). Following standard methodology, at pH 9.4 ATPase stain type I fibres are clear and type II fibres are darker, and at $\mathrm{pH}$ 4.6 ATPase stain type IIa fibres are also clear and type IIb are grey $[22,23]$. Fibre-type percentage (over 300 fibres) was determined using a microscope at 100 magnifying by two independent observers (Carl Zeiss, Essen, Germany). Because the reproducibility of these measurements was good (intra-class correlation coefficient of 0.92) [24], average data was used for analysis.

\section{Statistical analysis}

The statistical significance of differences between groups was assessed by 2-way analysis of variance, followed by posthoc contrast (Scheffe test) when appropriate. The KruskallWallis test was used to compare the fibre-types distribution between groups. A p-value $<0.05$ was considered significant. The mean values are based on the ones of each individual.

\section{Results}

\section{Clinical data}

Table 1 shows the clinical characteristics of the subjects studied. By design, BMI was different between groups. Yet, age was similar and all participants showed normal spirometric results (table 1). All patients with OSAS (both obese and nonobese) had severe disease, as indicated by the high

Table 1.-Clinical and functional characteristics of the different groups studied

\begin{tabular}{|c|c|c|c|c|c|c|c|c|}
\hline & \multicolumn{4}{|c|}{$\mathrm{BMI}>30 \mathrm{~kg} \cdot \mathrm{m}^{-2}$} & \multicolumn{4}{|c|}{$\mathrm{BMI}<30 \mathrm{~kg} \cdot \mathrm{m}^{-2}$} \\
\hline & Control & $\begin{array}{c}\text { OSAS } \\
\text { (at diagnosis) }\end{array}$ & $\begin{array}{c}\text { OSAS } \\
\text { (after CPAP) }\end{array}$ & $\begin{array}{l}\text { ANOVA } \\
\text { p-value }\end{array}$ & Control & $\begin{array}{c}\text { OSAS } \\
\text { (at diagnosis) }\end{array}$ & $\begin{array}{c}\text { OSAS } \\
\text { (after CPAP) }\end{array}$ & $\begin{array}{l}\text { ANOVA } \\
\text { p-value }\end{array}$ \\
\hline Subjects n & 4 & 6 & 7 & & 7 & 6 & 4 & \\
\hline Age yrs & $60 \pm 7$ & $41 \pm 4$ & $57 \pm 5$ & NS & $58 \pm 4$ & $54 \pm 3$ & $57 \pm 6$ & NS \\
\hline $\mathrm{BMI} \mathrm{kg} \cdot \mathrm{m}^{-2}$ & $31 \pm 0.2$ & $33 \pm 1.3$ & $32 \pm 1$ & NS & $23 \pm 1.3$ & $28 \pm 0.3^{*}$ & $26 \pm 0.6$ & 0.006 \\
\hline FEV1 \% reference & $82 \pm 10$ & $93 \pm 9$ & $82 \pm 8$ & NS & $82 \pm 10$ & $87 \pm 13$ & $82 \pm 13$ & NS \\
\hline FVC \% reference & $85 \pm 6$ & $92 \pm 10$ & $88 \pm 7$ & NS & $85 \pm 6$ & $93 \pm 12$ & $89 \pm 5$ & NS \\
\hline $\mathrm{AHI} \mathrm{h}^{-1}$ & NA & $57 \pm 8$ & $64 \pm 15$ & NS & NA & $67 \pm 8$ & $60 \pm 11$ & NS \\
\hline CPAP compliance $h$ & & & $7 \pm 1$ & & & & $7 \pm 1$ & \\
\hline
\end{tabular}

Data are presented as mean \pm SD. BMI: body mass index; FEV1: forced expiratory volume in one second; FVC: forced vital capacity; ANOVA: analysis of variance; CPAP: continuous positive airway pressure; AHI: apnoea/hypopnea index (recorded at the time of diagnosis in both groups of patients with obstructive sleep apnoea syndrome (OSAS)); NA: not available. ${ }^{*}$ indicates $\mathrm{p}<0.05$ compared to the control group; NS: nonsignificant. 
apnoea-hypopnea index (table 1). Patients treated with CPAP used it during $7 \pm 1 \mathrm{~h}$ per night (range, 5-8 h) (table 1).

\section{In vitro contractile properties of the genioglossus}

Table 2 presents the maximum twitch tension values determined in all participants. Differences between groups were not statistically significant, irrespective of the presence of obesity or treatment with CPAP. By contrast, it was observed that the in vitro fatigability characteristics of the GG were very different in the two groups of patients with OSAS studied (fig. 1). In nonobese patients, at diagnosis, the current authors' previous observations were reproduced [5] showing increased GG fatigability that was not observed in nonobese patients treated with CPAP $(\mathrm{p}<0.001)$ (fig. 1a). In contrast, in obese patients, neither before or after treatment with CPAP, GG fatigability was different from that recorded in obese controls ( $p=0.84$ ) (fig. 1b). Finally, GG endurance was similar in nonobese and obese controls $(\mathrm{p}=0.38)$.

\section{Genioglossus fibre-type distribution}

At diagnosis patients with OSAS showed a higher percentage of type II fibres than controls independently of obesity $(\mathrm{p}<0.05)$. This was mainly due to a increase in subtype IIb percentage (table 2 and 3). Interestingly, these differences were not observed between controls and patients on longterm treatment ( $>1 \mathrm{yr}$ ) with CPAP independently of obesity (table 2). For technical reasons there were available data in fibres II subtypes in three subjects of the CPAP obese group.

\section{Discussion}

To the best of the authors' knowledge, this is the first study investigating the potential effects of obesity upon GG structure and function in OSAS. The study found that: 1) GG resistance to fatigue was reduced only in nonobese patients; 2) GG endurance is similar in nonobese patients treated with CPAP as in control subjects; and, 3) the fibretype distribution of the GG was abnormal in all patients with OSAS (obese and nonobese). Overall, these results confirm previous observations from the present authors' laboratory [5] and others $[9,25,26]$ and open new questions of potential clinical relevance.

\section{Interpretation of findings}

The current study provides three main observations of interest, each of which need separate discussion. First, obesity
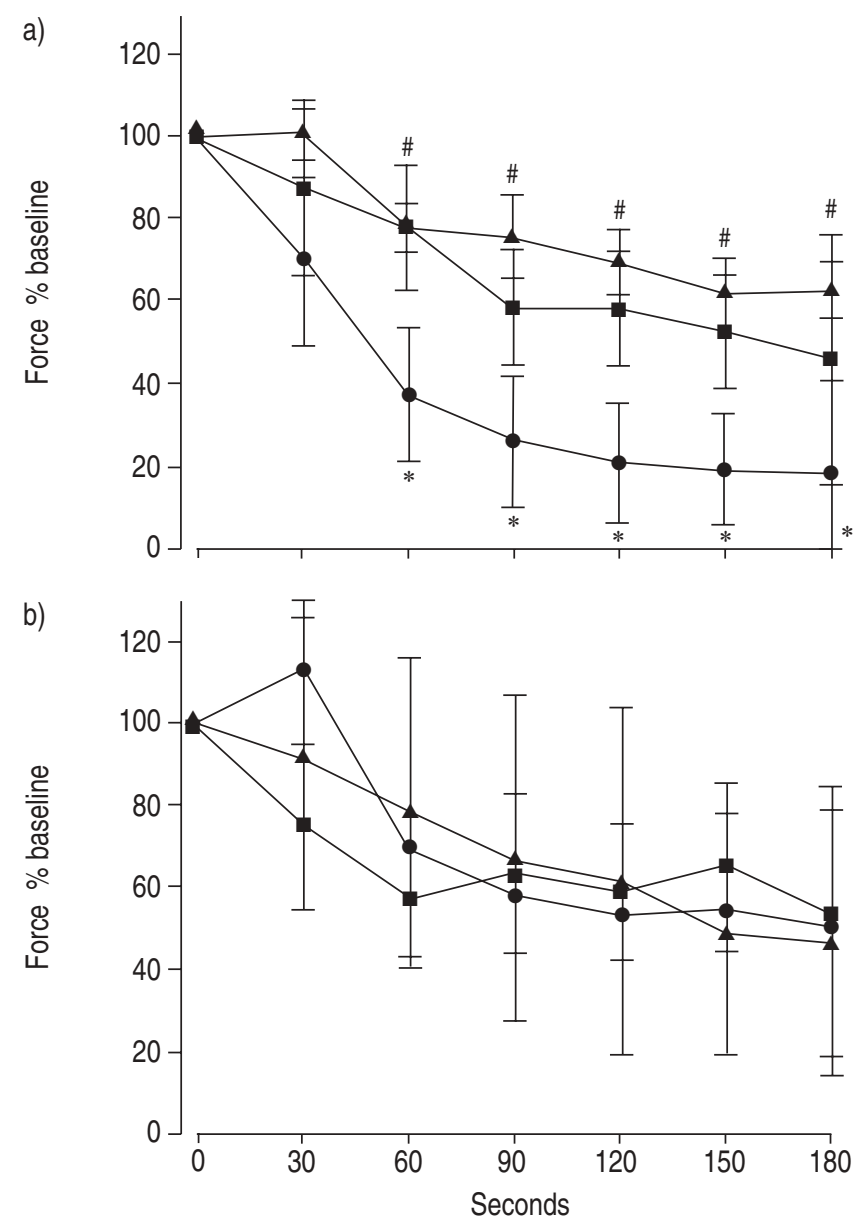

Fig. 1. - Time course of decrement in force production of the genioglossus (mean $\pm \mathrm{SD}$ ) in response to repetitive stimulation at $40 \mathrm{~Hz}$ in a) nonobese and b) obese subjects studied ( $\mathbf{\square}$ : control; $\boldsymbol{0}$ : obstructive sleep apnoea syndrome (OSAS) at diagnosis; $\boldsymbol{\Lambda}$ : OSAS after continuous positive airway pressure). Force was normalised to that produced during the first stimulus train. *: indicates $\mathrm{p}<0.05$ between untreated OSAS and controls; $\#$ : indicates $\mathrm{p}<0.05$ between untreated and treated patients with OSAS. For further explanations, see text.

did not influence the structure or function of the GG by itself (compare control subjects, with and without obesity, in table 2 and fig. 1). This contrasts with previous studies indicating that obesity can alter both the structure and function of skeletal muscle [7, 8]. Given the extraordinary plasticity of the muscle tissue, which rapidly changes in response to different functional demands [25], this observation suggests that obesity (in the absence of OSAS) does not

Table 2. - Structural and functional genioglossus results obtained in the different groups studied

\begin{tabular}{|c|c|c|c|c|c|c|c|c|}
\hline & \multicolumn{4}{|c|}{$\mathrm{BMI}>30 \mathrm{~kg} \cdot \mathrm{m}^{-2}$} & \multicolumn{4}{|c|}{$\mathrm{BMI}<30 \mathrm{~kg} \cdot \mathrm{m}^{-2}$} \\
\hline & Control & $\begin{array}{c}\text { OSAS } \\
\text { (at diagnosis) }\end{array}$ & $\begin{array}{c}\text { OSAS } \\
\text { (after CPAP) }\end{array}$ & $\begin{array}{c}\text { ANOVA } \\
\text { p-value }\end{array}$ & Control & $\begin{array}{c}\text { OSAS } \\
\text { (at diagnosis) }\end{array}$ & $\begin{array}{c}\text { OSAS } \\
\text { (after CPAP) }\end{array}$ & $\begin{array}{c}\text { ANOVA } \\
\text { p-value }\end{array}$ \\
\hline Subjects n & 4 & 6 & $7^{\#}$ & & 7 & 6 & 4 & \\
\hline Type II fibres \% & $27 \pm 5$ & $58 \pm 8^{*}$ & $37 \pm 5^{\oplus}$ & 0.02 & $44 \pm 10$ & $60 \pm 11 *$ & $42 \pm 9^{\top}$ & 0.04 \\
\hline Type IIa fibres $\%$ of type II & $92 \pm 10$ & $42 \pm 26^{*}$ & $99 \pm 1^{\bullet}$ & 0.002 & $89 \pm 18$ & $51 \pm 28 *$ & $97 \pm 3^{\circ}$ & 0.004 \\
\hline Type IIb fibres $\%$ of type II & $8 \pm 10$ & $58 \pm 26^{*}$ & $1 \pm 1^{\uparrow}$ & 0.002 & $11 \pm 18$ & $49 \pm 28 *$ & $3 \pm 3$ & 0.004 \\
\hline Normalised twitch tension $\mathrm{N} \cdot \mathrm{cm}^{-2}$ & $1.2 \pm 0.6$ & $0.7 \pm 0.6$ & $1.2 \pm 0.6$ & NS & $1.04 \pm 1.3$ & $0.9 \pm 0.6$ & $1.2 \pm 0.6$ & NS \\
\hline
\end{tabular}

Data are presented as mean \pm SD. BMI: body mass index; OSAS: obstructive sleep apnoea syndrome; ANOVA: analysis of variance. \#: for type II fibres subtypes the number of patients with available data were three (see table 3 ). *: indicates $\mathrm{p}<0.05$ compared to the control group; ${ }^{\circ}$ : indicates $\mathrm{p}<0.05$ compared to patients studied at diagnosis (before treatment with continuous positive airway pressure (CPAP) had been started); NS: nonsignificant. 
Table 3. - Fibre-type frequency for each subject in each group

\begin{tabular}{|c|c|c|c|c|c|}
\hline \multirow[t]{2}{*}{ Group } & \multirow[t]{2}{*}{ Subject } & \multicolumn{4}{|c|}{ Fibre type $\%$} \\
\hline & & I & II & II a & II b \\
\hline \multirow[t]{17}{*}{$\mathrm{BMI}<30$} & Control 1 & 55 & 45 & 38 & 7 \\
\hline & Control 2 & 42 & 58 & 58 & 0 \\
\hline & Control 3 & 63 & 37 & 33 & 4 \\
\hline & Control 4 & 55 & 45 & 23 & 22 \\
\hline & Control 5 & 74 & 26 & 26 & 0 \\
\hline & Control 6 & 64 & 36 & 36 & 0 \\
\hline & Control 7 & 67 & 33 & 33 & 0 \\
\hline & OSAS 1 & 64 & 36 & 36 & 0 \\
\hline & OSAS 2 & 34 & 66 & 15 & 51 \\
\hline & OSAS 3 & 30 & 70 & 20 & 50 \\
\hline & OSAS 4 & 28 & 72 & 37 & 35 \\
\hline & OSAS 5 & 46 & 54 & 23 & 27 \\
\hline & OSAS 6 & 36 & 64 & 38 & 26 \\
\hline & CPAP 1 & 60 & 40 & 40 & 0 \\
\hline & CPAP 2 & 56 & 44 & 41 & 3 \\
\hline & CPAP 3 & 70 & 30 & 30 & 0 \\
\hline & CPAP 4 & 46 & 54 & 52 & 2 \\
\hline \multirow[t]{17}{*}{$\mathrm{BMI}>30$} & Control 1 & 79 & 21 & 21 & 0 \\
\hline & Control 2 & 70 & 30 & 30 & 0 \\
\hline & Control 3 & 71 & 29 & 23 & 6 \\
\hline & Control 4 & 71 & 29 & 25 & 4 \\
\hline & OSAS 1 & 43 & 57 & 25 & 32 \\
\hline & OSAS 2 & 34 & 66 & 8 & 58 \\
\hline & OSAS 3 & 30 & 60 & 25 & 35 \\
\hline & OSAS 4 & 40 & 60 & 18 & 42 \\
\hline & OSAS 5 & 27 & 73 & 25 & 48 \\
\hline & OSAS 6 & 54 & 46 & 41 & 5 \\
\hline & CPAP 1 & 60 & 40 & 39 & 1 \\
\hline & CPAP 2 & 71 & 29 & 29 & 0 \\
\hline & CPAP 3 & 79 & 21 & 21 & 0 \\
\hline & CPAP 4 & 63 & 37 & NA & NA \\
\hline & CPAP 5 & 66 & 34 & NA & NA \\
\hline & CPAP 6 & 58 & 42 & NA & NA \\
\hline & CPAP 7 & 47 & 53 & NA & NA \\
\hline
\end{tabular}

BMI: body mass index; OSAS: obstructive sleep apnoea syndrome; CPAP: continuous positive airway pressure; NA: not available.

impose a higher work load upon the GG. This interpretation, however, has to be taken with caution due to the relatively small number of subjects studied.

Second, GG endurance was very low only in nonobese (as opposed to obese) patients with OSAS (fig. 1). It is well know that anatomical abnormalities of the upper airway are frequent in nonobese OSAS [27]. These can easily pose their GG at a mechanically disadvantageous position that favours the development of fatigue. In contrast, in obese patients with OSAS, the narrowing of the upper airway may be more related to the deposition of fat tissue around the neck [28] than to a mechanical impairment of their upper airway dilator muscles (fig. 1). The differences in GG endurance between both groups of patients should also be related to the cellular mechanisms involved in the process of muscle contraction and force generation. However, the capacity to generate force momentarily (twitch tension) was similar in both groups of patients (table 2). Thus, differences are likely to be related to those cellular processes involved in the maintenance (rather than the generation) of force, such as calcium release and uptake, and adenosine triphosphate and phosphocreatine synthesis and breakdown, among others.

Third, and finally, in keeping with previous studies [5, 9, 25, 26] the fibre-type distribution of GG was abnormal in patients with OSAS (table 2). At diagnosis, patients showed a predominance of fast twitch fibres. This percentage was modified in patients on CPAP treatment. It was found that the abnormal fibre-type distribution of the GG was independent of the presence of obesity, indicating that, somehow, this abnormal distribution is a characteristic of the disease itself. The closure of the upper airway that occurs repeatedly during sleep in these patients, as well as the arterial oxygen desaturation episodes that normally follow them, are two of the most characteristic features of OSAS [1, 29, 30]. Both can influence muscle structure through their respective mechanical $[25,31,32]$ or chemical [33] effects. Given that both were similarly distributed in the two groups of patients with OSAS studied here (table 1), the current authors postulate that one or both may underlie the changes observed in their GG structure (table 2). In keeping with this interpretation is the fact that treatment with CPAP (which prevents the apnoea and the arterial oxygen desaturation episodes) changes the fibre-type distribution in both groups (table 2). This hypothesis, however, does not exclude other potential mechanisms (systemic inflammation, genetic background of the individual) which will have to explored in future studies.

\section{Methodological limitations}

There are two potential limitations of the current study deserving comments. First, the small number of subjects included in the obese control and nonobese on CPAP groups (due to difficulties in recruiting this kind of specific subjects) recommends that the results should be interpreted with caution. Second, the biopsy was not performed in the same patient before and after CPAP therapy. This fact does not allow us to establish solid interpretations on the consequences of CPAP treatment, nor to perform correlations between structure and function changes. It also does not exclude that the results could be explained by individual variability. Ethical reasons do not allow such surgical procedures to be performed twice.

\section{Clinical implications}

Treatment with CPAP is highly effective in OSAS [34]. However, because it is cumbersome and expensive, new therapeutic alternatives are needed [35]. The present authors found that GG endurance was abnormal (and might be correctable by CPAP treatment) only in nonobese patients with OSAS (fig. 1). This may therefore indicate the need of different therapeutic strategies for these "different" pathogenic forms of OSAS (obese versus nonobese). For instance, serotoninergic drugs enhance upper airway electromyogram (EMG) activity in nonobese healthy volunteers [36] and seem to reduce the apnoea/hypopnoea index in nonobese patients with OSAS [37]. The eventual uncovering of the cellular mechanisms underlying the abnormal endurance capacity observed in the study in nonobese patients with OSAS may lead to more target-oriented pharmacological therapies. Alternatively, the fact that CPAP normalised GG endurance only in nonobese patients (fig. 1), raises the intriguing possibility of intermittent (weekly? monthly?) CPAP therapy. The current authors do not know yet what is the minimum duration of CPAP treatment required to achieve this effect, or for how long does this improvement last when CPAP support is stopped. However, these questions will have to be addressed in future studies. In any case, if efficacious, intermittent CPAP therapy would have tremendous clinical impact because about $50 \%$ of patients with OSAS are nonobese [1].

\section{Conclusions}

The current study suggests that only in nonobese subjects, the resistance to fatigue of the geniglossus is reduced (and 
might be correctable by continuous positive airway pressure). It was also observed that the fibre-type distribution of the geniglossus is abnormal in patients with obstructive sleep apnoea syndrome (independently of obesity). Therefore, these results suggest that, from a mechanistic perspective, there are at least two "different" forms of obstructive sleep apnoea syndrome and open new questions of potential clinical interest.

Acknowledgements. The authors thank the participants in the study for their collaboration and the technical staff of the Sleep Unit of the authors' Institution, particularly M. Bosch, for their help during the studies.

\section{References}

1. Douglas NJ, Polo O. Pathogenesis of obstructive sleep apnoea/hypopnoea syndrome. Lancet 1994; 344: 653-655.

2. Remmers JE, deGroot WJ, Sauerland EK, Anch AM. Pathogenesis of upper airway occlusion during sleep. $J$ Appl Physiol 1978; 44: 931-938.

3. Suratt PM, Mctier RF, Wilhoit SC. Upper airway muscle activation is augmented in patients with obstructive sleep apnea compared to that in normal subjects. Am Rev Respir Dis 1988; 137: 889-894.

4. Mezzanotte WS, Tangel DJ, White DP. Waking genioglossal electromyogram in sleep apnea patients versus normal controls (a neuromuscular compensatory mechanism). J Clin Invest 1992; 89: 1571-1579.

5. Carrera M, Barbé F, Sauleda J, Tomás M, Gómez C, Agustí AGN. Patients with obstructive sleep apnea exhibit genioglossus dysfunction that is normlized after treatment with continuous positive airway pressure. Am J Respir Crit Care Med 1999; 159: 1960-1966.

6. Young T, Palta M, Dempsey J, Skatrud J, Weber S, Badr S. The ocurrence of sleep-disordered breathing among middleaged adults. $N$ Engl $J$ Med 1993; 328: 1230-1235.

7. Wade AJ, Marbut MM, Round JM. Muscle fibre type and aetiology of obesity. Lancet 1990; 335: 805-808.

8. Schwartz AR, O'Donnell CP, Baron J, et al. The hypotonic upper airway in obstructive sleep apnea. Role of structures and neuromuscular activity. Am J Respir Crit Care Med 1998; 157: 1051-1057.

9. Sériès F, Côté C, Simoneau J-A, et al. Physiologic, metabolic, and muscle fiber type characteristics of musculus uvulae in sleep apnea hypopnea syndrome and in snorers. J Clin Invest 1995; 95: 20-25.

10. Malhotra A, Pillar G, Fogel RB, et al. Genioglossal but not palatal muscle activity relates closely to pharyngeal pressure. Am J Respir Crit Care Med 2000; 162: 1058-1062.

11. Scardella AT, Krawciw N, Petrozzino JJ, Co MA, Santiago TV, Edelman NH. Strength and endurance characteristics of the normal human genioglossus. Am Rev Respir Dis 1993; 148: 179-184.

12. Kapuniai L, Andrew D, Crowell D, Pearce J. Identifying sleep from self-reports. Sleep 1988; 11: 430-436.

13. Glenmark B. Skeletal muscle fiber types, physical performance, physical activity and attitude to physical activity in women and men. A follow-up from age 16-27. Acta Physiol Scand 1994; 151: Suppl. 623, 1-42.

14. Flier JS. Obesity. In: Braunwald E, Fauci AS, Kasper DL, Hauser SL, Longo DL, Jameson JL, eds. Harrison's Principles of Internal Medicine. New York, McGraw Hill, 2001: 479-486.

15. Sanchis J, Casan P, Castillo J, Gonzalez N, Palenciano L, Roca J. Guidelines for forced spirometry [Normativa para la práctica de la espirometría forzada]. Arch Bronconeumol 1989; 25: 132-142.

16. Roca J, Sanchis J, Agustí-Vidal A, et al. Spirometric reference values for a mediterranean population. Bull Eur Physiopathol Respir 1986; 22: 217-224.

17. Van Lunteren E, Manubay P. Contractile properties of feline genioglossus, sternohyoid and sternothyroid muscles. $J$ Appl Physiol 1992; 72: 1010-1015.

18. Van Lunteren E, Vafaie H. Force potentiation in respiratory muscles: comparision of diaphragm and sternohyoid. $J$ Appl Physiol 1993; 264: R1095-R1100.

19. Brass EP, Scarrow AM, Ruff LJ, Masterson KA, Van Lunteren E. Carnitine delays rat skeletal muscle fatigue in vitro. J Appl Physiol 1993; 75: 1595-1600.

20. Segal SS, Faulkner JA. Temperature-dependent physiological stability of rat skeletal muscle in vitro. Am J Physiol 1985; 248: C265-C270.

21. Burke RE, Levine DN, Zajac FEI, Tsairis P, Engel WK. Mammalian motor units: physiological-histochemical correlation in three types in cat gastrocnemius. Science 1971; 174: 709-712.

22. Sauleda J, Gea J, Orozco-Levy M, Minguella J, Aguar C, Agustí AGN. Structure and function relationships of the respiratory muscles. Eur Respir J 1998; 11: 1-6.

23. Dubowitz V, Brooke MH. Histological and histochemical stains and reactions. In: Dubowitz V, Brooke MH, eds. Muscle Biopsy: A Modern Approach. London, WB Saunders Co., 1973: pp. 20-33.

24. Bland JM, Altman DG. Statistical methods for assessing agreement between two methods of clinical measurement. Lancet 1986; 1: 307-310.

25. Smirne $\mathrm{S}$, Iannaccone $\mathrm{S}$, Ferini-Strambi L, Comola $\mathrm{M}$ Colombo E, Nemni R. Muscle fibre type and habitual snoring. Lancet 1991; 337: 597-599.

26. Ferini-Strambi L, Smirne S, Moz H, Sferrazza B, Iannaccone S. Muscle fibre type and obstructive sleep apnea. Sleep Research Online 1998; 1: 24-27.

27. Ferguson KA, Ono T, Lowe AA, Ryan CF, Fleetham JA. The relationship between obesity and craniofacial structure in obstructive sleep apnea. Chest 1995; 108: 375-381.

28. Mortimore IL, Marshall I, Wraith PK, Sellar RJ, Douglas NJ. Neck and total body fat deposition in nonobese and obese patients with sleep apnea compared with that in control subjects. Am J Respir Crit Care Med 1998; 157: 280-283.

29. White DP. Pathophysiology of obstructive sleep apnoea. Thorax 1995; 50: 797-804.

30. Safwan Badr M. Pathophysiology of upper airway obstruction during sleep. Clin Chest Med 1998; 19: 2132.

31. Friberg D, Ansved T, Borg K, Carlson-Nordlander B, Larsson H, Svanborg E. Histological indications of a progresive snorers disease in an upper airway muscle. $\mathrm{Am}$ J Respir Crit Care Med 1998; 157: 586-593.

32. Edstrom L, Larsson H, Larsson L. Neurogenic effects on the palatopharyengeal muscle in patients with obstructive sleep apnoeas: a muscle biopsy study. J Neurology Neurosurg Psychiatry 1992; 55: 916-920.

33. Kimura H, Niijima M, Edo H, Tatsumi K, Honda $\mathrm{Y}$, Kuriyama T. The effect of hypoxic depression on genioglossal muscle activity in healthy subjects and obstructive sleep apnea patients. Sleep 1993; 16: S135-S136.

34. Sullivan CE, Berthon-Jones M, Issa FG, Eves L. Reversal of obstructive sleep apnoea by continuous positive airway pressure applied through the nares. Lancet 1981; 1: 862-865.

35. Strohl KP, Redline S. Recognition of obstructive sleep apnea. Am J Respir Crit Care Med 1996; 154: 279-289.

36. Sunderram J, Parisi R, Strobel R. Serotonergic stimulation of the genioglossus and the response to nasal continuous positive airway pressure. Am J Respir Crit Care Med 2000; 161: 925-929.

37. Kraiczi H, Hedner J, Dahlöf P, Ejnell H, Carlson J. Effect of serotonin uptake inhibition on breathing during sleep and daytime symptoms in obstructive sleep apnea. Sleep 1999; 22: $62-67$. 